\title{
Validation of chemical analyses of atmospheric deposition on forested sites in Europe: 2. DOC concentration as an estimator of the organic ion charge
}

\author{
Rosario MOSELLO*, Tiziana AMORIELLO ${ }^{1)}$, Sue BENHAM ${ }^{2)}$, Nicholas CLARKE ${ }^{3)}$, John DEROME4), \\ Kirsti DEROME ${ }^{4}$, Gerrit GENOUW ${ }^{5}$, Nils KOENIG ${ }^{6}$, Arianna ORRÙ, Gabriele TARTARI, Anne THIMONIER ${ }^{7)}$, \\ Erwin ULRICH ${ }^{8)}$ and Antti-Jussi LINDROOS ${ }^{4}$
}

\author{
CNR Institute of Ecosystem Study, L.go Tonolli 50, 28922 Verbania, Italy \\ ${ }^{1)}$ CRA Experimental Institute for Plant Nutrition, Via della Navicella 2/4, 00184 Roma, Italy \\ ${ }^{2}$ Forest Research Laboratory, Farnham Surrey, UK \\ ${ }^{3)}$ Norwegian Forest and Landscape Institute, Hogskolevein 12, 1432 Ås, Norway \\ ${ }^{4)}$ Finnish Forest Research Institute, P.O. Box 16, 96301 Rovaniemi, Finland \\ ${ }^{5}$ Research Institute for Nature and Forêts, Geraardsbergen, Belgium \\ ${ }^{6}$ Nordwestdeutsche Forstliche Versuchsanstalt, Graetzelstr. 2, 37079 Goettingen, Germany \\ ${ }^{7)}$ WSL, Birmensdorf, Switzerland \\ ${ }^{8)}$ Office National des Forêts, Boulevard de Constance, 77300 Fontainebleau, France \\ *e-mail corresponding author: r.mosello@ise.cnr.it
}

\begin{abstract}
A Working Group on Quality Assurance/Quality Control of analyses in laboratories active in the chemical analysis of atmospheric deposition and soil water has been created within the framework of the Integrated Co-operative Programme on Assessment and Monitoring of Air Pollution Effects on Forests (UN-ECE/ICP Forests) and the EU/Forest Focus Programme (Regulation 2152/2003). This paper is a follow up to an earlier paper dealing with the validation of chemical analyses, in which validation techniques (ion balance, comparison between measured and calculated conductivity, $\mathrm{Na} / \mathrm{Cl}$ ratio and relationship between different forms of $\mathrm{N}$ ) were tested on a set of real analysis data obtained from different laboratories. This paper focuses on the validation of chemical analysis of samples containing high dissolved organic carbon (DOC) concentrations ( $>5 \mathrm{mg} C \mathrm{~L}^{-1}$ ), where the ion balance criterion fails because of the presence of weak organic acids. About 6000 chemical analyses of bulk open field, throughfall and stemflow samples, which contained complete sets of all ion concentrations, conductivity and DOC, produced in 8 different laboratories, were used to calculate empirical relationships between DOC and the difference between the sum of cations and the sum of anions, with the aim to evaluate a formal charge per mg of organic C. Regression coefficients were obtained for data from each laboratory, as well as for all the data combined. The coefficients were further tested using an independent set of data from each country. The differences between the individual laboratory and the overall regression coefficients are discussed. The results are also considered in the light of formal charge values for DOC/TOC obtained in studies on freshwater. The formal DOC charge proved to be useful for estimating the contribution of organic acids in the ion balance test, thus considerably improving the applicability of the ion balance as a validation criterion for samples with high DOC values.
\end{abstract}

Key words: atmospheric deposition chemistry, chemical analysis, validation criteria, European network, DOC

\section{INTRODUCTION}

The Working Group on Quality Assurance/Quality Control for laboratories participating in ICP Forests and EU Forest Focus was created to assist laboratories responsible for the analysis of atmospheric deposition, soil and soil solution, and leaves/needles, within the programmes. The validation of chemical analyses of atmospheric deposition collected on the monitoring plots was considered to be an important task of the working group, these questions being covered to some extent already in the manual of the ICP Forests programme (Ulrich et al. 2006). In a previous paper (Mosello et al. 2005), four validation criteria were proposed and tested on a set of 5000 analyses carried out in seven laboratories in five different countries. The results clearly demonstrated that the comparison between measured and calculated conductivity was the most widely applicable criterion for the validation of water samples, as it was equally applicable to open field (bulk and wet only), throughfall and stemflow deposition. On the other hand, although the ion balance of the most common cations $\left(\mathrm{H}^{+}, \mathrm{NH}_{4}^{+}\right.$, $\left.\mathrm{Ca}^{++}, \mathrm{Mg}^{++}, \mathrm{Na}^{+}, \mathrm{K}^{+}\right)$and anions $\left(\mathrm{HCO}_{3}^{-}, \mathrm{SO}_{4}^{--}, \mathrm{NO}_{3}^{-}, \mathrm{Cl}^{-}\right)$ is reliable in the case of bulk open field and wet-only samples (in the following referred to as BOF and WET), it is not applicable in the case of throughfall and stemflow (THR and STF) samples owing to the presence of significant amount of organic anions, collectively measured as dissolved organic carbon (DOC).

The other two validation criteria (the $\mathrm{Na} / \mathrm{Cl}$ ratio and a consistency test of the concentrations of different forms of nitrogen) are applicable to the four types of 
deposition, but their descriptive properties are definitely lower than those of the tests based on conductivity and ion balance.

The present paper aims to investigate the DOC concentration of different types of precipitation, and to evaluate the possibility of using the DOC concentrations to evaluate the ionic contribution of the organic anions in solution. The difference between the sum of cations and the sum of anions is therefore compared with the DOC concentration in order to evaluate whether DOC can be used to evaluate the existing ionic differences.

As systematic errors are a possible source of bias in the cation and anion determinations, the data analyses were performed on a set of data provided by 8 different laboratories; it is very unlikely that the same systematic errors occur in all of the laboratories. In the second step, the regression coefficients between $\left(\sum_{\text {cat }}-\sum_{\text {an }}\right)$ and DOC for the different laboratories, and for different types of solution, are discussed in relation to the analytical methods used and the geographic and climatic characteristics of the sample plots. Finally, the results are discussed in relation to other attempts to quantify the relative contribution of organic anions in the ion balance of atmospheric deposition and freshwater.

\section{METHODS}

\subsection{Sources of data, type of solutions used and analytical methods}

Names and acronyms of the laboratories involved in the study are given in table 1 , and the distribution of the sample plots in figure 1.

The type of solutions (BOF, THR, STF) and the number of samples of each type, after exclusion of samples that did not pass the validation criteria, are listed in table 2. The results were validated at the national level by the National Focal Centres of the ICP Forests and Forest Focus programmes, and submitted as official results for the years 2002-2003. In addition, the samples analysed by the individual laboratories were further stratified according to the type of tree cover on the plot (broadleaves BL, conifers $\mathrm{CON}$ ), and the relative importance of salts of marine origin using a $\mathrm{Cl}^{-}$concentration of $50 \mu \mathrm{eq} \mathrm{L} \mathrm{L}^{-1}$ as the threshold to distinguish between

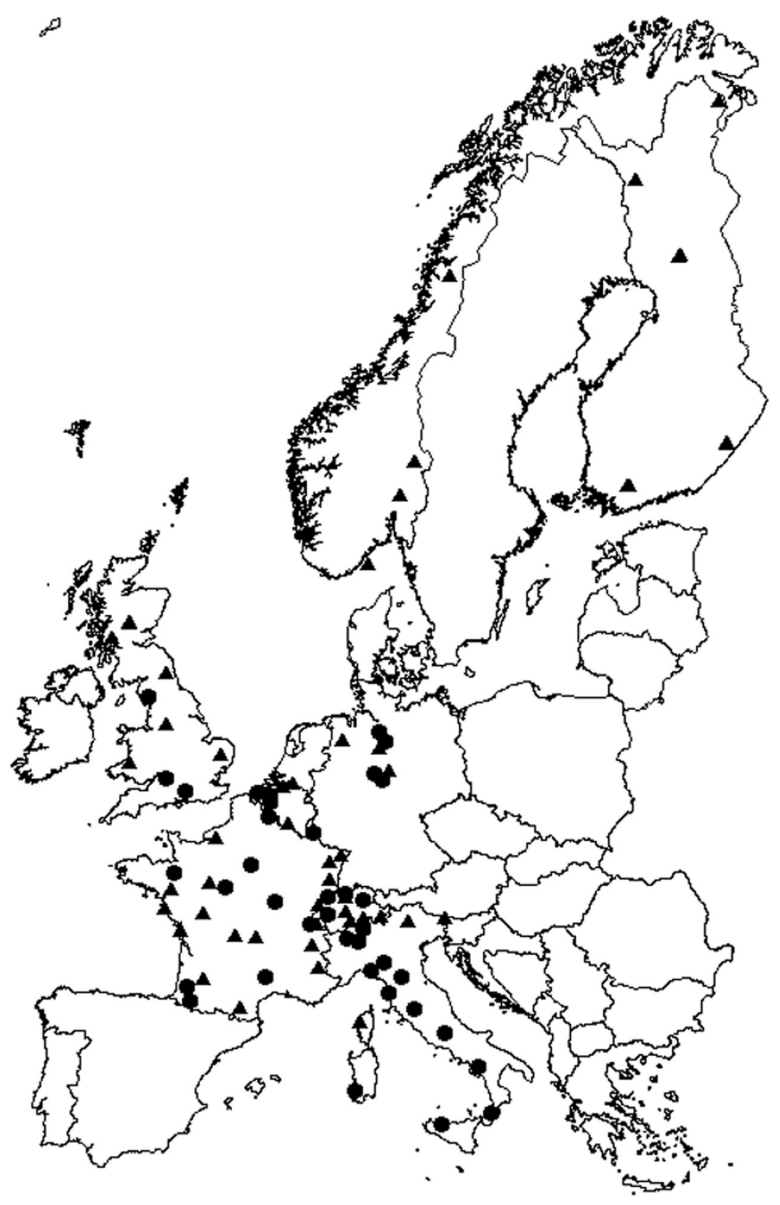

Fig. 1. Location of the sampling plots: dots broadleaves, triangles conifers.

samples with strong or weak marine influence. Table 2 also shows the number of samples forming a subset of independent analyses used to validate the effects of the DOC correction on the results of the ion balance calculations. The analytical methods used in each laboratory are listed in table 3. All the laboratories follow a QA/QC program, and participated in the two intercomparison exercises performed within the framework of the programmes (Mosello et al. 2002; Marchetto et al. 2006).

Tab. 1. Laboratories participating in the study.

\begin{tabular}{ll}
\hline BE & Laboratory of Soil Science, Ghent (main ions and DOC) \\
BE & Research Institute for Nature and Forest, Geraardsbergen (pH and conductivity) \\
CH & WSL, Birmensdorf, Switzerland \\
DE & Nordwestdeutsche Forstliche Versuchsanstalt, Göttingen, Germany \\
FI & Finnish Forest Research Institute, Rovaniemi, Finland \\
FR & SGS Laboratories Wolff-Environment, Evry, France \\
IT & C.N.R. Institute of Ecosystem Study, Verbania Pallanza, Italy \\
NO & Norwegian Forest Research Institute, Ås, Norway \\
UK & Forest Research Institute, Alice Holt Lodge, Farnham Surrey, Great Britain \\
\hline
\end{tabular}


Tab. 2. Number of analysis sets supplied by the individual countries used for the statistical analysis on each type of solution (number of analysis sets used for testing the regressions in parentheses). BOF $=$ bulk open field, THR $=$ throughfall, $\mathrm{STF}=$ stemflow.

\begin{tabular}{|c|c|c|c|c|c|c|c|c|c|c|}
\hline Tree cover & $\begin{array}{c}\text { Type } \\
\text { solution }\end{array}$ & $\mathrm{BE}$ & $\mathrm{CH}$ & $\mathrm{DE}$ & FI & FR & IT & NO & UK & Total \\
\hline Conifer & $\mathrm{BOF}$ & 144 & 106 & 92 & 162 & & 214 & 167 & 79 & 964 \\
\hline Conifer & THR & $\begin{array}{l}186 \\
(60)\end{array}$ & $\begin{array}{c}70 \\
(111)\end{array}$ & $\begin{array}{r}243 \\
(443)\end{array}$ & $\begin{array}{c}121 \\
(104)\end{array}$ & $\begin{array}{c}306 \\
(514)\end{array}$ & $\begin{array}{l}214 \\
(82)\end{array}$ & $\begin{array}{c}216 \\
(236)\end{array}$ & $\begin{array}{c}301 \\
(396)\end{array}$ & $\begin{array}{c}1657 \\
(1946)\end{array}$ \\
\hline Broadleaf & $\mathrm{BOF}$ & 199 & 136 & 88 & & & 604 & & 78 & 1105 \\
\hline Broadleaf & STF & $\begin{array}{c}275 \\
(120)\end{array}$ & & & & 143 & 179 & & & $\begin{array}{c}597 \\
(120)\end{array}$ \\
\hline Broadleaf & THR & $\begin{array}{l}253 \\
(91)\end{array}$ & $\begin{array}{l}126 \\
(148)\end{array}$ & $\begin{array}{l}121 \\
(210)\end{array}$ & & 372 & $\begin{array}{c}299 \\
(300)\end{array}$ & & 283 & $\begin{array}{l}1454 \\
(749)\end{array}$ \\
\hline Total & & $\begin{array}{l}1057 \\
(271)\end{array}$ & $\begin{array}{c}438 \\
(259)\end{array}$ & $\begin{array}{c}544 \\
(653)\end{array}$ & $\begin{array}{c}283 \\
(104)\end{array}$ & $\begin{array}{c}821 \\
(514)\end{array}$ & $\begin{array}{l}1510 \\
(382)\end{array}$ & $\begin{array}{c}383 \\
(236)\end{array}$ & $\begin{array}{c}741 \\
(396)\end{array}$ & $\begin{array}{r}5777 \\
(2815)\end{array}$ \\
\hline
\end{tabular}

Tab. 3. Main analytical methods used by the laboratories.

\begin{tabular}{lccccccccc}
\hline Lab. & $\mathrm{pH}$ & Conductivity & Alkalinity & $\mathrm{NH}_{4}^{+}$ & $\mathrm{Ca}^{++}, \mathrm{Mg}^{++}, \mathrm{Na}^{+}, \mathrm{K}^{+}$ & $\mathrm{Cl}^{-}$ & $\mathrm{NO}_{3}^{-}$ & $\mathrm{SO}_{4}^{--}$ & $\mathrm{DOC}^{-}$ \\
\hline BE & POT GEN & CORR & POT 2EP & IC & AAS & IC & IC & IC & THIR \\
CH & POT LIS & CORR & POT Gran & CF GD & ICP OES & IC & IC & IC & THIR \\
DE & POT LIS & CORR & POT Gran & CF Phe & ICP OES & CF AgCl & CF Cd & ICP OES & THIR \\
FI & POT LIS & $25^{\circ} \mathrm{C}$ & POT 2EP & CF GD & IC & IC & IC & IC & THIR \\
FR & POT GEN & CORR & POT 2EP & IC & IC & IC & IC & IC & THIR \\
IT & POT LIS & CORR & POT Gran & SPEC Phe & IC & IC & IC & IC & THIR \\
NO & POT GEN & $25^{\circ} \mathrm{C}$ & POT 4.5 & CF GD & ICP OES & IC & IC & IC & THIR \\
UK & POT LIS & $25^{\circ} \mathrm{C}$ & POT 2EP & CF Phe & ICP OES & IC & IC & IC & THIR \\
\hline
\end{tabular}

Legend

\begin{tabular}{ll}
\hline Acronym & Method description \\
\hline POT GEN & $\mathrm{pH}$ - potentiometric with unspecified electrode \\
POT LIS & $\mathrm{pH}$ - potentiometric with low ionic strength electrode \\
$25^{\circ} \mathrm{C}$ & Conductivity - measurement performed at $25^{\circ} \mathrm{C}$ \\
CORR & Conductivity - measurement performed at different temperature and corrected to $25^{\circ} \mathrm{C}$ \\
POT & Gran Alkalinity - potentiometric titration with Gran method for extrapolation of the equivalent point \\
POT 2EP & Alkalinity - potentiometric titration with two end point extrapolation of the equivalent point \\
POT 4.5 & Alkalinity - potentiometric titration with one end point extrapolation of the equivalent point, results corrected for acid addition \\
SPEC Phe & Ammonium - spectrophotometry indophenol blue method \\
CF Phe & Ammonium - continuous flow analysis with indophenol blue method \\
CF GD & Ammonium - continuous flow analysis with gas diffusion \\
IC & Ion chromatography with chemical or electrochemical eluent suppression \\
ICP OES & Inductively coupled plasma optical emission spectrometry \\
CF AgCl & Chloride - continuous flow analysis with Ag/AgCl electrode \\
CF Cd & Nitrate - continuous flow analysis with Cd reduction \\
AAS & Atomic absorption spectrophotometry \\
THIR & Thermal combustion and IR detection \\
\hline
\end{tabular}

\subsection{Validation checks outlined in the ICP Forests manual}

As prescribed in the ICP Forests manual (Ulrich et al. 2006), each laboratory is to perform a check of the ion balance (only BOF and WET) and a comparison between the measured (CM) and calculated (CE) conductivity (on all types of samples) in order to validate the analysis results. A third check is performed to confirm that the $\mathrm{Na} / \mathrm{Cl}$ ratio is between 0.5 and 1.5. According to the 
instructions given in the manual, if the thresholds of these checks are exceeded then the analyses must be repeated; if the result is confirmed and the thresholds are still exceeded, the results must be accepted. The relationships used in the validation are the concentration of anions vs the concentration of cations $\left(\sum_{\mathrm{cat}} v s \sum_{\mathrm{an}}\right)$, and the measured conductivity vs the calculated conductivity $(\mathrm{CM} v s \mathrm{CE})$ :

$$
\begin{gathered}
\Sigma_{\text {cat }}=\left[\mathrm{Ca}^{++}\right]+\left[\mathrm{Mg}^{++}\right]+\left[\mathrm{Na}^{+}\right]+\left[\mathrm{K}^{+}\right]+\left[\mathrm{NH}_{4}^{+}\right]+\left[\mathrm{H}^{+}\right] \\
\Sigma_{\text {an }}=\left[\mathrm{HCO}_{3}^{-}\right]+\left[\mathrm{SO}_{4}^{--}\right]+\left[\mathrm{NO}_{3}^{-}\right]+\left[\mathrm{Cl}^{-}\right] \\
\mathrm{CE}=\sum \lambda_{\mathrm{i}} \mathrm{Ci}
\end{gathered}
$$

$\mathrm{i}=\mathrm{H}^{+}, \mathrm{Ca}^{++}, \mathrm{Mg}^{++}, \mathrm{Na}^{+}, \mathrm{K}^{+}, \mathrm{NH}_{4}^{+}, \mathrm{HCO}_{3}^{-}, \mathrm{SO}_{4}^{--}, \mathrm{NO}_{3}^{-}$, $\mathrm{Cl}^{-} ; \lambda_{\mathrm{i}}=$ equivalent conductance at infinite dilution of the ion i (Tab. 4). As the concentrations are expressed in $\mu$ eq $\mathrm{L}^{-1}, \lambda_{\mathrm{i}}$ is given as $\mathrm{kS} \mathrm{cm}^{2} \mathrm{eq}^{-1}$ in order to obtain the conductivity in $\mu \mathrm{S} \mathrm{cm}^{-1}$.

Bicarbonate is calculated from total alkalinity (Gran's alkalinity) in relation to the $\mathrm{pH}$, assuming that it is determined only by inorganic carbon species, proton and hydroxide:

$$
\text { TAlk }=-\left[\mathrm{H}^{+}\right]+\left[\mathrm{OH}^{-}\right]+\left[\mathrm{HCO}_{3}^{-}\right]+\left[\mathrm{CO}_{3}^{--}\right]
$$

This definition is not completely correct in the case of high DOC values $\left(>5 \mathrm{mg} \mathrm{C} \mathrm{L}^{-1}\right.$ ) (see discussion in Section 4.2).

The ion balance check is based on the test of the electroneutrality of the water samples: the total number of negative and positive charges must be equal. The constants required to transform the units used in the ICP Forests Deposition Programme into $\mu \mathrm{eq} \mathrm{L} \mathrm{L}^{-1}$ are given in table 4. Using $\sum_{\text {cat }}$ and $\sum_{\text {an }}$ to indicate the concentrations
( $\mu$ eq $\mathrm{L}^{-1}$ ) of cations and anions, respectively, the percentage difference (PD) is:

$$
\mathrm{PD}=100 \times\left(\sum_{\text {cat }}-\Sigma_{\text {an }}\right) /\left(0.5 \times \sum_{\text {cat }}+\sum_{\text {an }}\right)
$$

High concentrations of dissolved organic matter, if present, must, be taken into account. Organic matter in deposition samples acts as an organic anion, producing a systematic bias in which the concentrations of cations are higher than those of inorganic anions. Corrections based on DOC concentration developed e.g. by Oliver $e t$ al. (1983) cannot be directly applied to throughfall and stemflow samples because they were primarily based on stream, lake, bog and ground water. Corrections for the presence of dissolved organic matter, specific for each site and each type of sample (bulk deposition, throughfall etc.), can be developed on the basis of earlier analyses on deposition samples.

The percentage difference between the measured and calculated conductivity is given by the ratio:

$$
\mathrm{CD}=100 \times(\mathrm{CE}-\mathrm{CM}) / \mathrm{CM}
$$

In deposition samples with low ionic strength (below 0.1 meq $^{-1}$ ), the $\mathrm{CD}$ value between the measured and calculated conductivity should be no more than $2 \%$ (Miles \& Yost 1982). For an ionic strength higher than $0.1 \mathrm{meq} \mathrm{L}^{-1}$ and lower than 0.5 meq $\mathrm{L}^{-1}$, the Davies correction of the activity of each ion can be used, as proposed e.g. by A.P.H.A., A.W.W.A., W.E.F. (2005). The acceptance threshold values of $\mathrm{PD}$ and $\mathrm{CD}$ adopted in the ICP Forests manual vary according to the ion concentrations, as shown in table 5 .

Tab. 4. Concentration units used, factors for transforming concentration into $\mu \mathrm{eq} \mathrm{L}^{-1}$, and equivalent conductance at infinite dilution of the individual ions.

\begin{tabular}{lccc}
\hline & Unit & Factor to $\mu \mathrm{eq} \mathrm{L}{ }^{-1}$ & Equivalent conductance at $25^{\circ} \mathrm{C} \mathrm{kS} \mathrm{cm}^{2} \mathrm{eq}^{-1}$ \\
\hline $\mathrm{pH}$ & & $10^{(6-\mathrm{pH})}$ & 0.3500 \\
Ammonium & $\mathrm{mg} \mathrm{N} \mathrm{L}^{-1}$ & 71.39 & 0.0735 \\
Calcium & $\mathrm{mg} \mathrm{L}^{-1}$ & 49.9 & 0.0595 \\
Magnesium & $\mathrm{mg} \mathrm{L}^{-1}$ & 82.24 & 0.0531 \\
Sodium & $\mathrm{mg} \mathrm{L}^{-1}$ & 43.48 & 0.0501 \\
Potassium & $\mathrm{mg} \mathrm{L}^{-1}$ & 25.28 & 0.0735 \\
Alkalinity & $\mu \mathrm{eq} \mathrm{L}^{-1}$ & 1 & 0.0445 \\
Sulphate & $\mathrm{mg} \mathrm{S} \mathrm{L}^{-1}$ & 62.37 & 0.0800 \\
Nitrate & $\mathrm{mg} \mathrm{N} \mathrm{L}^{-1}$ & 71.39 & 0.0714 \\
Chloride & $\mathrm{mg} \mathrm{L}^{-1}$ & 28.2 & 0.0764 \\
\hline
\end{tabular}

Tab. 5. Acceptance threshold values in data validation based on the ion balance and conductivity.

\begin{tabular}{lcc}
\hline Conductivity $\left(25^{\circ} \mathrm{C}\right)$ & $\mathrm{PD}$ & $\mathrm{CD}$ \\
\hline$<10 \mu \mathrm{S} \mathrm{cm}^{-1}$ & $\pm 20 \%$ & $\pm 30 \%$ \\
$<20 \mu \mathrm{S} \mathrm{cm}^{-1}$ & $\pm 20 \%$ & $\pm 20 \%$ \\
$>20 \mu \mathrm{S} \mathrm{cm}^{-1}$ & $\pm 10 \%$ & $\pm 10 \%$ \\
\hline
\end{tabular}


The third relationship tested is the ratio between $\mathrm{Na}^{+}$ and $\mathrm{Cl}^{-}$; assuming that most of these ions are derived from sea spray; a ratio relatively close to the marine value (0.86) should be expected (Keene et al. 1986). If other sources of these ions are involved, then the range of "acceptable" values is widened from 0.5 to 1.5 (Ulrich et al. 2006).

\subsection{Hypothesis tested and statistical methods}

The goal of the data elaboration is to verify whether a relationships exists between $\Sigma_{\text {cat }}-\sum_{\text {an }}$ (hereafter indicated as $\Delta$ ) and the DOC concentration, and whether the regression coefficients are affected by the analysis methods used in the laboratories, the type of solution, the type of tree cover and the concentration of marinederived $\mathrm{NaCl}$. The overall aim of this study is to select the best estimate of the coefficients for general use in evaluation of the ion balance. The hypotheses listed in table 6 were tested.

Analysis of covariance (ANCOVA) was used to test the statistical significance of the differences among the laboratories, between the types of sample, between the samples from broadleaf/conifer plots, and between "marine" and "non-marine" samples (Hypotheses 1-5). This modelling technique represents an integration of the analysis of variance and regression analysis, and it is appropriate when there are both quantitative and qualitative (grouping) factors. The basic advantage of this is a reduction in the bias caused by the differences between the groups. The ANCOVA model treats both betweengroup and regression variance as systematic components. The statistical model is:

$$
\Delta_{\mathrm{ij}}=\delta_{0}+\tau_{\mathrm{i}}+\delta_{1} \sum\left(\mathrm{x}_{\mathrm{ij}}-\mathrm{x}_{\mathrm{i}}\right)+\varepsilon_{\mathrm{ij}}
$$

where:

$\Delta_{\mathrm{ij}}=$ dependent variable score $\left(\Sigma_{\text {cat }}-\sum_{\text {an }}\right)$ of the $\mathrm{j}^{\text {th }}$ unit in the $\mathrm{i}^{\text {th }}$ treatment

$\delta_{0}=$ population mean (of dependent variable) common to all observations

$\tau_{\mathrm{i}}=$ effect of treatment:

- laboratory i (a constant associated with all units in laboratory i)
- solutions from broadleaf/conifer plots

- "marine" and "non marine" solutions

- type i of solutions (THR, ST)

$\delta_{1}=$ linear regression coefficient of $\mathrm{y}$ on $\mathrm{x}$

$\mathrm{x}_{\mathrm{i}}=$ mean of all units on covariate DOC

$\mathrm{x}_{\mathrm{ij}}=$ covariate score for the $\mathrm{j}^{\text {th }}$ unit in the $\mathrm{i}^{\text {th }}$ treatment

$\varepsilon_{i j}=$ error component associated with the $j^{\text {th }}$ unit in the $i^{\text {th }}$ treatment.

Multi-linear regressions were used to construct a statistical model for analyzing the linear relationship between the regressions $\left(\mathrm{Org}^{-}=\mathrm{b} \times \mathrm{DOC}+\mathrm{a}\right)$ and the geographical and climatic information (Hypothesis 7). The statistical model is:

$\mathrm{Y}_{\mathrm{k}}^{1,2}=\alpha_{0}+\alpha_{1} \mathrm{X}_{1 \mathrm{k}}+\alpha_{2} \mathrm{X}_{2 \mathrm{k}}+\alpha_{3} \mathrm{X}_{3 \mathrm{k}}+\alpha_{4} \mathrm{X}_{4 \mathrm{k}}+\alpha_{5} \mathrm{X}_{5 \mathrm{k}}+\varepsilon_{\mathrm{k}}$

where:

$\mathrm{Y}^{1,2}{ }_{\mathrm{k}}=$ dependent variable $(1=$ slope, $2=$ intercept $)$

$\alpha_{0}{ }^{k}=$ general mean effect (intercept)

$\mathrm{X}_{1 \mathrm{k}}=$ latitude

$\mathrm{X}_{2 \mathrm{k}}=$ longitude

$\mathrm{X}_{3 \mathrm{k}}=$ altitude

$\mathrm{X}_{4 \mathrm{k}}=$ precipitation

$\mathrm{X}_{5 \mathrm{k}}=$ mean air temperature

$\alpha_{i}=$ linear regression coefficient of $\mathrm{Y}$ on $\mathrm{X}_{\mathrm{i}}$ $(\mathrm{I}=1, \ldots, 5)$

$\varepsilon_{\mathrm{k}} \quad=$ random error.

Both ANCOVA and regression analysis are analysed using the general linear models (GLM) procedure. This procedure uses the method of least squares to fit the general linear model and handles the models relating one or several continuous dependent variables to one or several independent variables. The independent variables may be either classification variables, which divide the observation into discrete groups, or continuous variables.

\section{RESULTS}

\subsection{Validation of the results of the chemical analyses}

The data submitted by each country had already been validated by the National Focal Centres, although not necessarily using the criteria proposed in the ICP Forests

Tab. 6. Hypotheses tested on the data set comprising analyses made by different laboratories and on different types of solutions (1-4), and on the regression coefficients $\beta_{1}$ (formal charge) of the significant regression $\Delta v s$ DOC.
1) Are there differences in the data sets produced in different laboratories?
2) Are there differences between the data sets for different types of solution?
3) Are there differences between the data sets for solutions sampled on broadleaf or conifer plots?
4) Are there differences between the data sets for deposition with a high or a low marine salt content?
5) Are there differences between the coefficients $\left(\beta_{1}\right)$ obtained for different types of solution?
6) Are there differences between the coefficients for different plots?
7) Are there differences between the coefficients related to the geographic/climatic conditions of the plots? 
manual (UN ECE 2004; Ulrich et al. 2006) as they are not mandatory. For the purpose of this paper, the data sets were "cleaned" to remove (1) incomplete analysis sets, and (2) results that did not pass the test of conductivity (see Section 2.2). Samples with excessively high $\Sigma_{\text {cat }}, \Sigma_{\text {an }}$ or DOC values were also removed in order to eliminate skewness in the data distribution and to obtain normal (Gaussian) distributions. This, of course, will have to be taken into account when the regression coefficients are adopted, and only used for samples falling within the range of values given in tables $7 \mathrm{a}$ and $7 \mathrm{~b}$. These procedures resulted in the elimination of about $15 \%$ of the submitted data. The number of analysis sets used in the statistical analysis of each type of solution and laboratory/country are reported in table 2 . The number of analysis sets used in generating the regression coefficients and the number used in testing them are given separately.

\subsection{Description and statistics of the data}

The main statistical indicators of the set of data for each country are given separately for BL and $\mathrm{CON}$ in tables $7 \mathrm{a}$ and $7 \mathrm{~b}$. The deposition samples with higher solute concentrations in all three types of solution (BOF, THR, STF) are from those plots in Italy, UK, Norway and Belgium that are influenced by marine spray, while the lowest ion concentrations are from Finland and Switzerland. The solute concentrations increased in the order BOF, THR, STF. The DOC concentration also increased regularly in the order BOF, THR and STF (mean \pm s.d. $2 \pm 1,8 \pm 6,11 \pm 7 \mathrm{mg} \mathrm{C} \mathrm{L}^{-1}$, respectively), with the highest values occurring in the samples from Italy and Belgium.

The statistical analysis for the THR data sets indicated highly significant differences between the data sets (Hypothesis 1 in Tab. 6), with $30 \%$ of the variability explained by the variable "laboratory". Contrast analysis showed four pairs of countries with no differences: DE and FI; DE and IT; FI and IT; FI and UK. These differences reflect, at least partially, the analytical (systematic and/or random) errors within each laboratory. On the other hand, there were no statistical differences between the three data sets (DE, FR, IT) in the case of the STF solutions.

Comparison between the THR and STF data sets was possible only in the case of the countries BE, FR and IT, and in all three cases the differences were significant (Hypothesis 2 in Tab. 6), with a relative contribution to the total variance of 19, 4 and 2\%, respectively.

Comparison between the THR data sets collected on broadleaf and conifer plots was possible for six countries (BE, DE, FR, IT, UK, CH) and the differences were highly significant in all cases (Hypothesis 3 in Tab. 6), although the contribution to the total variance of the model was very small $(0.5 \%)$.

In the case of marine and non-marine solutions
(Hypothesis 4 in Tab. 6), the contribution was 3\% and $9 \%$ of the total variance in the model for THR (8 labs) and STF solutions (3 labs), respectively.

\subsection{Significance and regression coefficients of the relationships $\triangle$ vs $D O C$}

The regressions between $\Delta v s$ DOC were not significant for the deposition samples collected in the open field (BOF) in any of the individual laboratory's datasets, so no further statistical analyses were carried out on the BOF data sets. On the other hand, the regressions were significant for $\mathrm{BL}$ and $\mathrm{CON}$ in all the laboratories for both throughfall and stemflow samples (Tab. 7a, b). The values of the slope (THR) ranged between 4.48 and $7.60 \mu \mathrm{eq}\left(\mathrm{mg} \mathrm{DOC}^{-1}\right.$ for broadleaves, while they were systematically lower for conifers (range $3.33-5.41 \mu$ eq $(\mathrm{mg} \mathrm{DOC})^{-1}$ (Fig. 2). This suggests that there were differences in the composition of the organic acids in throughfall collected under the two types of tree cover. The values for the stemflow solutions, which were available only from $\mathrm{BL}$ and for 3 laboratories, ranged between 5.19 and $5.72 \mu \mathrm{eq}(\mathrm{mg} \mathrm{DOC})^{-1}$. The mean THR values for all the set of data were 6.80 and $4.17 \mu \mathrm{eq}(\mathrm{mg}$ DOC) $)^{-1}$ for BL and CON, respectively.

There were no significant differences between the slope $\beta_{1}$ of the regressions $\Delta$ vs DOC for the STF and THR solutions; this comparison is limited to the solutions from BL plots in BE, FR, and IT for which both THR and STF data were available (Hypothesis 5 in Tab. 6).

As it was not originally intended to compare the $\beta_{1}$ values obtained at the individual plot level, in some cases there was not enough data to obtain significant values for the regression coefficient. For this reason, only those plots with more than 16 analysis sets were investigated. The values of the regression slopes and intercepts for throughfall on broadleaf and conifer plots and stemflow on broadleaf plots are presented in table 8 .

Overall the mean values of the slope $\beta_{1}$ (the physical significance of which is the formal charge in $\mu$ eq per $\mathrm{mg}$ of DOC) values ranged between $4.7 \pm 1.6$ and $5.9 \pm 2.0$ $\mu$ eq $(\mathrm{mg} \mathrm{DOC})^{-1}$, without any statistically significant differences between them (Hypothesis 6 in Tab. 6).

The final aim of this work was to look for differences between the coefficients related to geographic (latitude, longitude, altitude) and climatic (mean annual temperature and annual precipitation) variables (Hypothesis 7 in Tab. 6). The statistical analyses did not indicate any significant relationships between the formal charge and these variables. It is not possible to verify the possible negative effect of the broad approach taken in defining the type of tree cover (broadleaves and conifers) and/or the associated errors in the chemical data. 


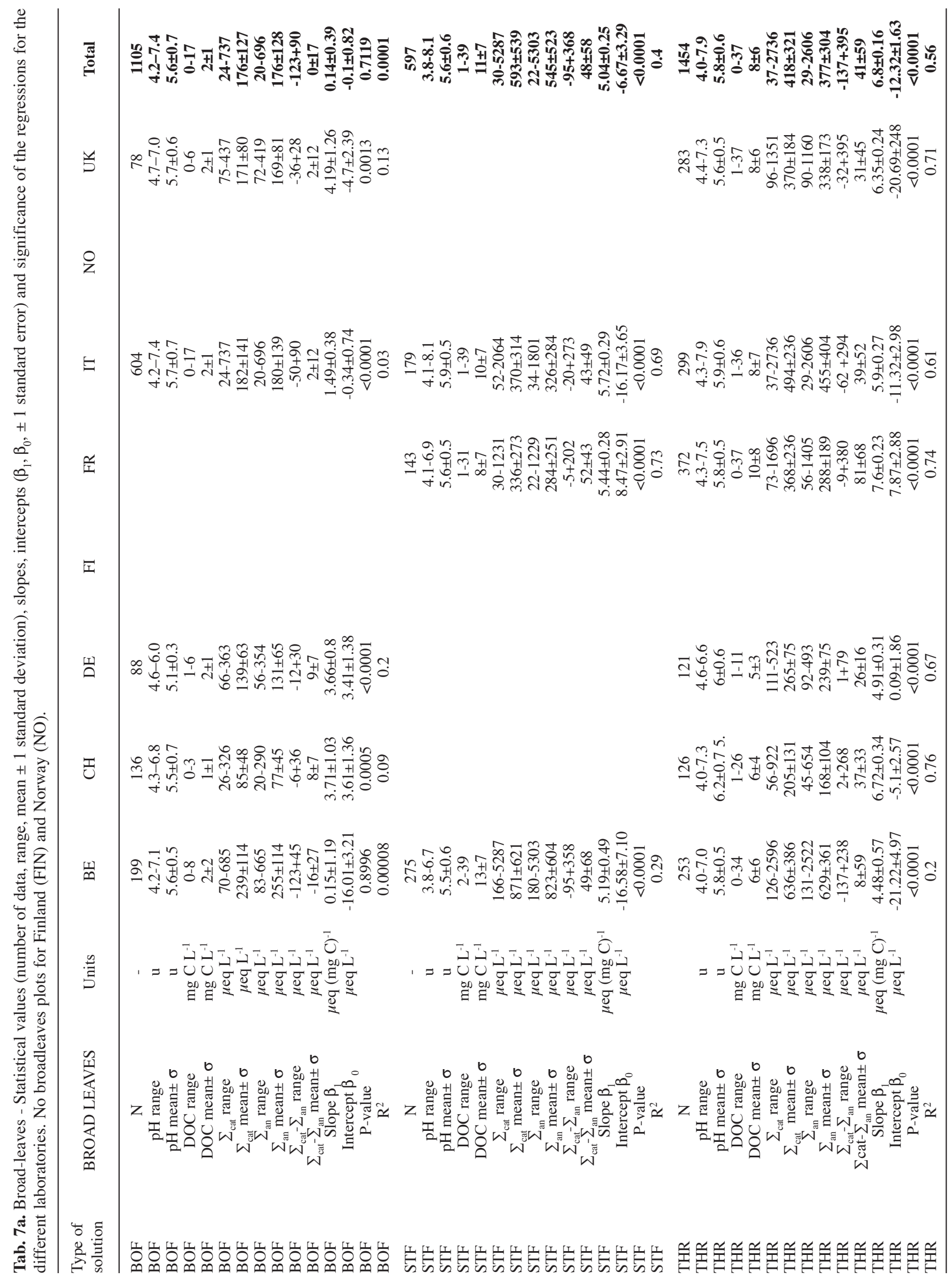




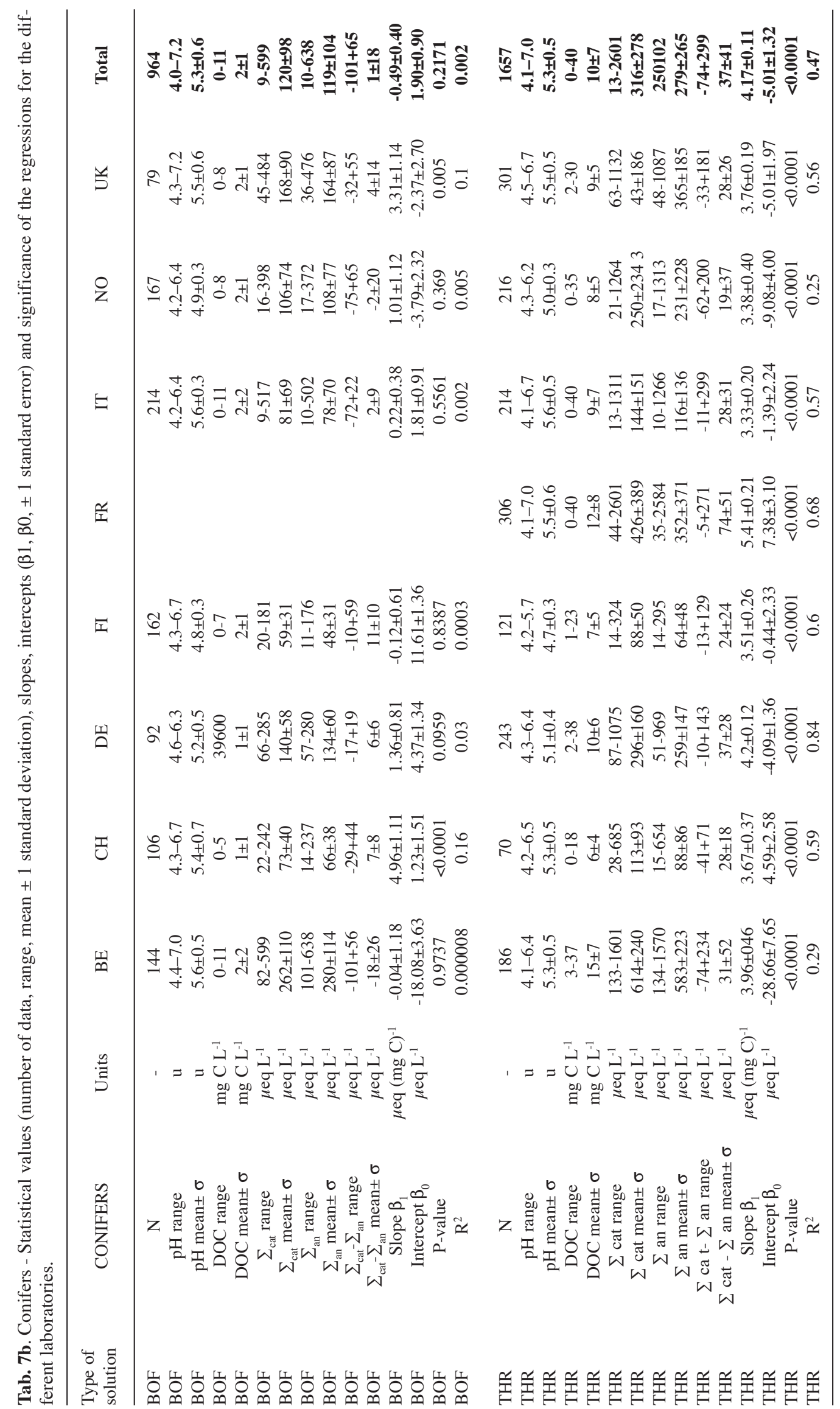


THR slope $\beta_{1}$ ( $\mu$ eq $\mathrm{mg} \mathrm{DOC}^{-1}$ )

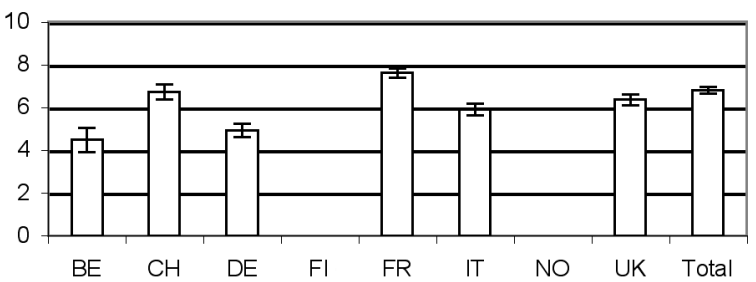

$\overline{\mathrm{TH}} \overline{\mathrm{R}}$ slope $\bar{\beta}_{1}\left(\mu \mathrm{eq} \mathrm{mg} \overline{\mathrm{DOC}}^{-1}\right)$

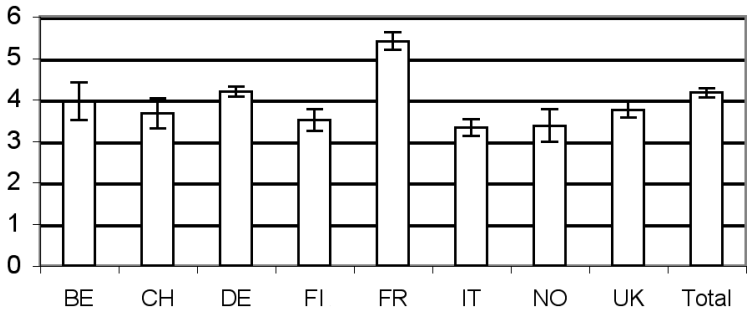

STF slope $\beta_{1}$ ( $\mu$ eq $\mathrm{mg} \mathrm{DOC}^{-1}$ )

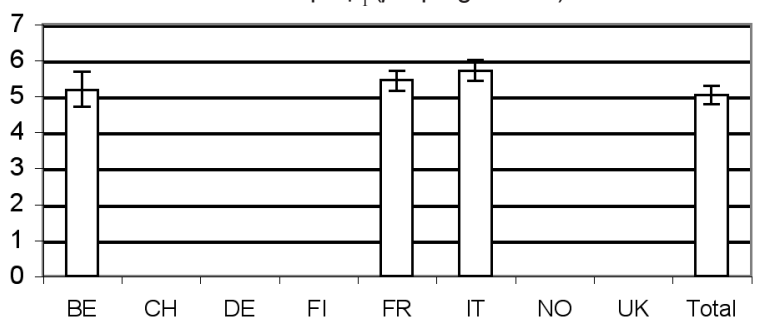

THR intercept $\beta_{0}\left(\mu\right.$ eq $\left.L^{-1}\right)$

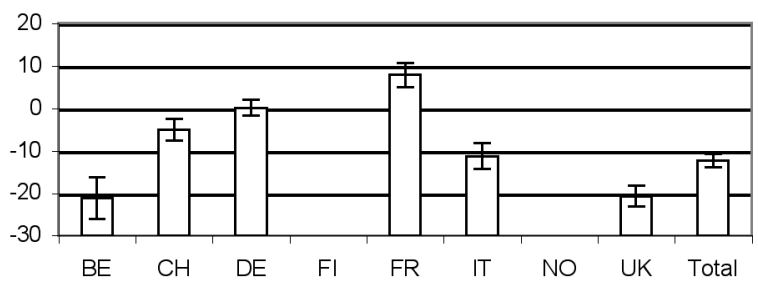

THR intercept $\beta_{0}\left(\mu\right.$ eq $\left.L^{-1}\right)$

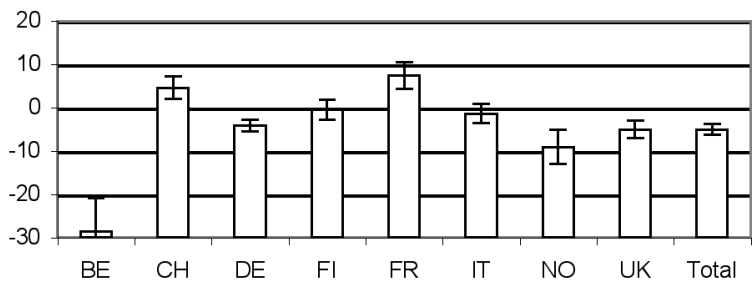

STF intercept $\beta_{0}(\mu$ eq L-1)

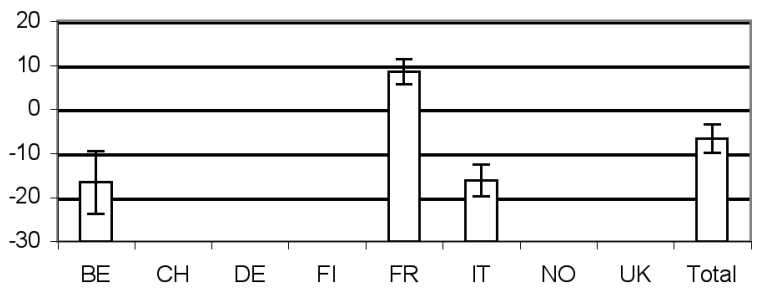

Fig. 2. Coefficient of regressions between $\Delta$ and DOC, stratified on laboratories, type of solution and type of vegetation. Legend: CON conifers, BL broadleaves, THR throughfall, STF stemflow.

Tab. 8. Range, an values and standard deviations of $\beta_{1}$ and $\beta_{0}$ for the different types of solution on the two types of plot.

\begin{tabular}{lccc}
\hline & $\begin{array}{c}\text { Throughfall } \\
\text { conifer }\end{array}$ & Throughfall broadleaf & Stemflow broadleaf \\
\hline number of plots & 46 & 32 & 11 \\
$\beta_{1} \pm \sigma$ & $4.73 \pm 1.58$ & $5.91 \pm 1.99$ & $4.95 \pm 1.60$ \\
range $\beta_{1}$ & $2.33,9.08$ & $2.22,10.65$ & $2.98,8.34$ \\
$\beta_{0} \pm \sigma$ & $-3.06 \pm 15.87$ & $-4.46 \pm 14.81$ & $-4.97 \pm 13.08$ \\
range $\beta_{0}$ & $-48.47,34.85$ & $-43.46,27.21$ & $-22.61,14.42$ \\
\hline
\end{tabular}

\section{DISCUSSION}

\subsection{Testing the regression coefficients}

In order to test the improvement in the validity of the ion balance after correction for the contribution of the DOC formal charge, an independent data set was used to test the procedure on the analyses carried out in some of the countries (IT, UK, FR, DE, NO) and for the two types of tree cover (BL and $\mathrm{CON}$ ). Evaluation of the ionic charge associated with $\mathrm{DOC}\left[\mathrm{Org}^{-}\right]$was done for each country using both regression coefficients (slope and intercept) calculated from the data of the same country, and the mean values of the regression coefficients obtained from the pooled data, separately for BL and CON (Tab. 7a, b):

$$
\left[\mathrm{Org}^{-}\right]=\beta_{1} \times \mathrm{DOC}+\beta_{0}
$$

where [Org-] and $\beta_{0}$ units are $\mu \mathrm{eq} \mathrm{L}^{-1}, \mathrm{DOC}$ and $\beta_{1}$ units are $\mathrm{mg} \mathrm{C} \mathrm{L}^{-1}$ and $\mu$ eq $(\mathrm{mg} \mathrm{C})^{-1}$. 
The effects of the two corrections were evaluated on the basis of the ion balance test (Tab. 5). The DOC correction substantially increased the number of acceptable analyses (Tab. 9), producing a percentage of validated analyses close to that validated using the conductivity test. The percentage of validated analyses obtained from the country regression coefficients and from the mean of all the data were comparable, with the highest differences in the case of FR and IT (conifers). This result, together with the high representativity of the deposition sample, indicated that the pooled regression coefficients are, in fact, widely applicable. The effects of the two different DOC corrections on the frequency distribution of the differences between the sum of cations and the corrected sum of anions are shown in figure 3. In this case, the positive effect of the DOC correction is also clear.

\subsection{Comparison with the formal charge of DOC obtained in other studies}

Several studies have investigated the ion charge contribution of total and dissolved organic carbon (TOC and DOC) in freshwater, but no studies are available for atmospheric deposition. The freshwater studies have mainly concentrated on evaluating the contribution of TOC/DOC to alkalinity, and the relative importance of weak and strong acidity in freshwater acidification.

Two main approaches have been used: the relationship between $\sum_{\text {cat }}-\sum_{\text {an }}$ and TOC (e.g., Köhler et al. 2000), and depiction of the acidity of organic anions in terms of dissociation constants, using both the monoprotic and triprotic approaches (e.g., Oliver 1983;
Schecher \& Driscoll 1987; Kopáček et al. 2000). A third approach estimates the dissociation of organic acid [Org] using total alkalinity and DOC (Köhler et al. 2000).

Two conclusions presented in the above studies are relevant for the aims of the present paper:

1) Total alkalinity values are affected by the contribution from TOC/DOC due to the protonation of weak acids [Org] ${ }^{-}$, in addition to the contribution of dissolved inorganic carbon species and of other proton acceptors $\mathrm{A}^{-}$(e.g. $\mathrm{Al}^{\mathrm{n}+}$, phosphate, borate, etc).

TAlk $=-\left[\mathrm{H}^{+}\right]+\left[\mathrm{OH}^{-}\right]+\left[\mathrm{HCO}_{3}^{-}\right]+\left[\mathrm{CO}_{3}^{--}\right]+\left[\mathrm{Org}^{-}\right]+\left[\mathrm{A}^{-}\right]$

where the units are in $\mu$ eq $\mathrm{L}^{-1}$.

It is difficult to quantify the contributions of weak acids and other proton acceptors by ordinary analytical techniques, as they consist of a mixture of chemical compounds, which may vary in relation to the type of water (freshwater/atmospheric deposition) and several other factors (seasonality, hydrology, type of deposition, etc.). The first quantification of the contribution of [Org] as $4.6 \mu \mathrm{eq}(\mathrm{mg} \mathrm{DOC})^{-1}$ was proposed by Oliver et al. (1983) for freshwater, on the basis of empirical data. This value has been widely applied in subsequent papers, mainly based on empirical data sets.

2) The DOC formal charge is $\mathrm{pH}$-dependent, and increases with increasing $\mathrm{pH}$ (Munsen \& Gherini 1993; Köhler et al. 2000).

The values of the formal charge, $\beta_{1}$, calculated by different authors for TOC/DOC in freshwater are summarised in table 10. Values of $\beta_{1}$ range from 3.1 to 12.9 $\mu$ eq $(\mathrm{mg} \text { TOC })^{-1}$, with a very clear relationship with $\mathrm{pH}$.

Tab 9. Percent of analyses validated on the base of the conductivity test and ion balance (1) not using DOC correction, (2) using [Org-] charge calculated from the regression of each country and (3) using [ $\left.\mathrm{Org}^{-}\right]$charge calculated from the mean values from all the countries. $n=$ number of validated analyses.

\begin{tabular}{lcccccc}
\hline & N. samples & $\begin{array}{c}\text { Conductivity } \\
\text { test } \\
\%\end{array}$ & $\begin{array}{c}\text { Ion balance } \\
\text { test }(1) \\
\%\end{array}$ & $\begin{array}{c}\text { Ion balance } \\
\text { test }(2) \\
\%\end{array}$ & $\begin{array}{c}\text { Ion balance } \\
\text { test }(3) \\
\%\end{array}$ \\
\hline BE & BL STF & 120 & 81 & 60 & 92 & 93 \\
BE & BL THR & 91 & 82 & 70 & 77 & 87 \\
BE & CON & 60 & 90 & 73 & 92 & 73 \\
CH & BL & 148 & 58 & 27 & 93 & 89 \\
CH & CON & 111 & 56 & 20 & 87 & 78 \\
DE & BL & 210 & 91 & 67 & 93 & 93 \\
DE & CON & 443 & 92 & 52 & 89 & 95 \\
FI & BL & - & - & - & - & - \\
FI & CON & 104 & 51 & 16 & 60 & 53 \\
FR & BL & - & - & - & - & - \\
FR & CON & 514 & 100 & 17 & 88 & 72 \\
IT & BL & 300 & 100 & 61 & 84 & 81 \\
IT & CON & 82 & 91 & 26 & 70 & 73 \\
NO & BL & - & - & - & - & - \\
NO & CON & 236 & 87 & 36 & 78 & 84 \\
UK & BL & - & - & - & - & - \\
UK & CON & 396 & 100 & 58 & 67 & 66 \\
\hline
\end{tabular}



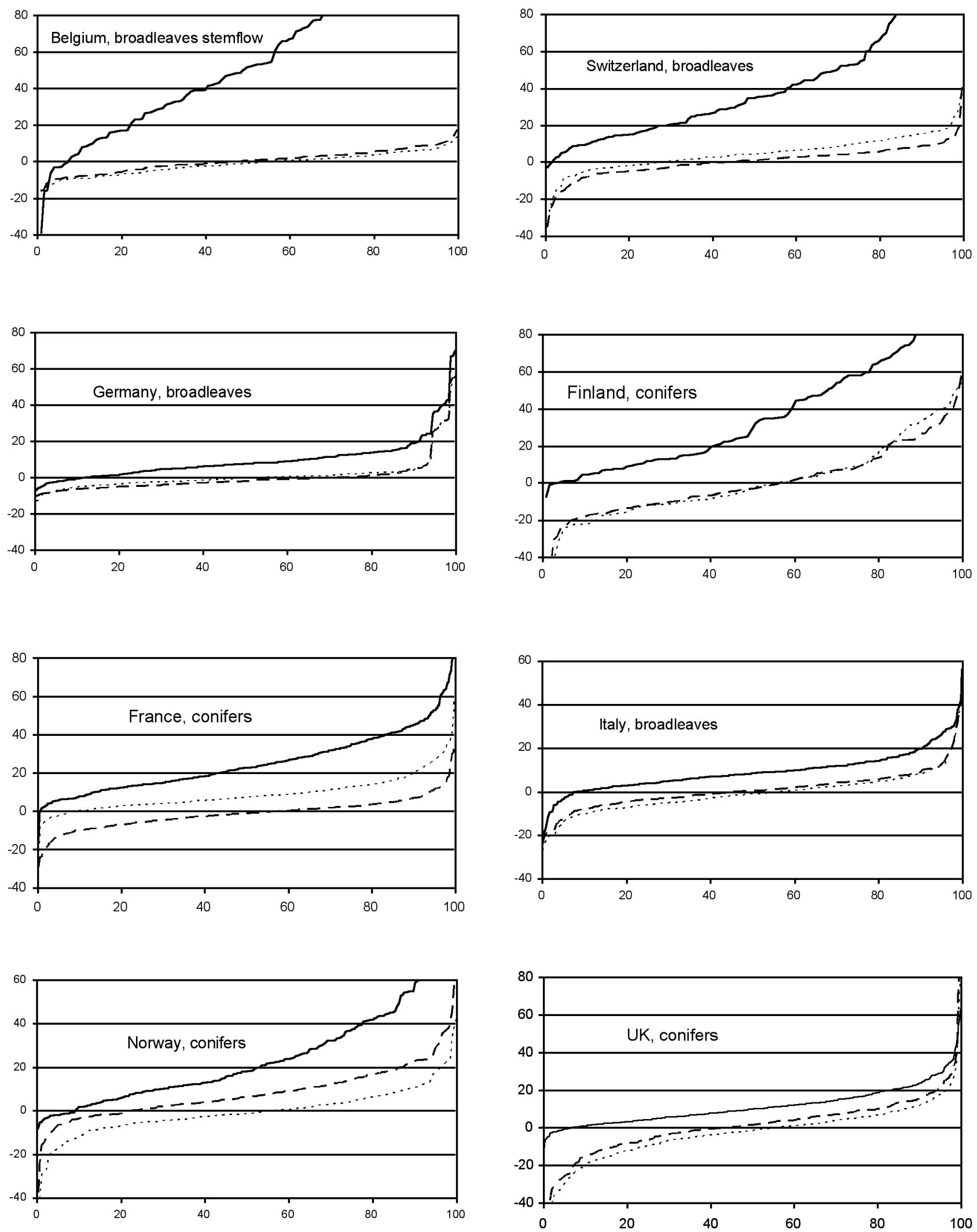

Fig. 3. Examples of cumulated frequency curves for $\Delta$ without and with the DOC correction (line: original data; dotted line: DOC correction using coefficients calculated from the regression of each country; dashed line: DOC correction using coefficients calculated from the mean values from all the countries). 
Tab. 10. Comparison between formal charge values (mean values $\pm 1 \sigma$ ) of TOC calculated in different studies.

\begin{tabular}{cccc}
\hline $\begin{array}{c}\text { Formal charge } \\
\text { mep }(\mathrm{mg} \text { TOC) }\end{array}$ & pH range & Type of waters & Reference \\
\hline $4.4 \pm 0.1$ & $4.0-4.5$ & Swedish surface waters & Köhler et al. 2000 \\
$5.8 \pm 0.5$ & $5.0-5.5$ & & \\
$8.4 \pm 1.5$ & $6.0-6.5$ & & \\
$12.9 \pm 2.4$ & $7.0-7.5$ & Adirondack, NY & Driscoll et al. 1994 \\
3.1 & $4.0-4.5$ & & \\
4.6 & $5.0-5.5$ & & Kortelainen 1992 \\
11.7 & $6.0-6.5$ & & \\
5.2 & $4.0-4.5$ & & \\
6.4 & $5.0-5.5$ & & Finnish waters \\
8.1 & $6.0-6.5$ & & Hopáček et al. 2000 \\
10.3 & $7.0-7.5$ & Bohemian forest streams & \\
$6.2 \pm 0,8$ & $3.8-6,3$ (median 4.32$)$ & Streams, Northern Sweden al. 2001 \\
$8.6 \pm 0.8$ & $4.2-5,5$ & & \\
\hline
\end{tabular}
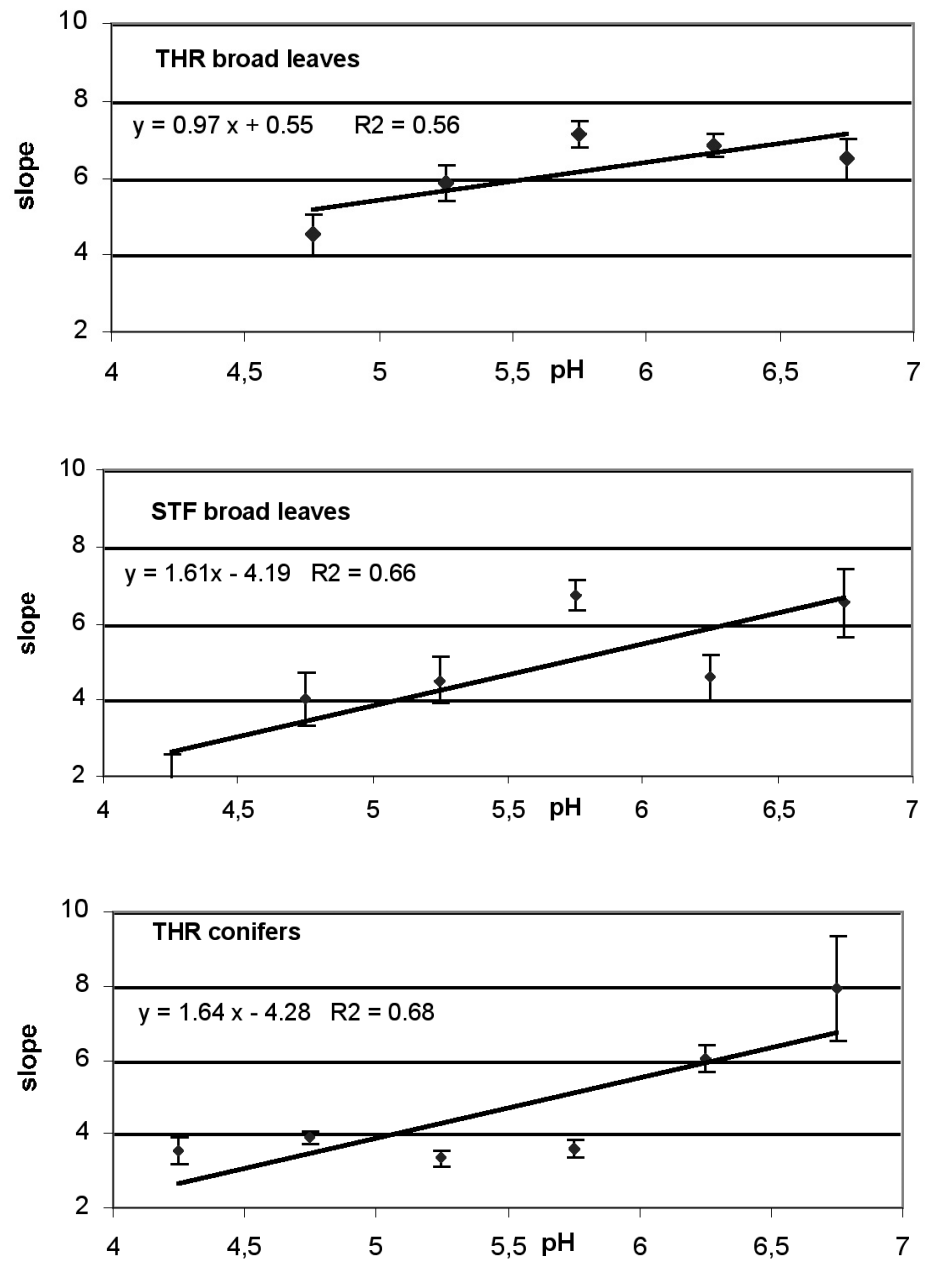

Fig. 4. Variation in the values of $\beta_{1}$ (formal charge, $\mu$ eq (mg DOC) $)^{-1} \pm 1$ standard error $v s \mathrm{pH}$. 
The range for atmospheric deposition obtained in our study at the individual plot level was between 2.2 and $10.6 \mu \mathrm{eq}(\mathrm{mg} \mathrm{DOC})^{-1}$ (Tab. 8).

\subsection{Testing the dependence of the DOC formal charge $\left(\beta_{1}\right)$ on $\mathrm{pH}$}

In order to investigate the dependence of the $\beta_{1}$ values on $\mathrm{pH}$, the set of data from each laboratory, separately for THR BL, STF BL and THR CON, were pooled and grouped within successive $\mathrm{pH}$ ranges of 0.5 units; the value of $\beta_{1}$ and the relative standard error was calculated for each range and plotted against the mean value of $\mathrm{pH}$ of each range (Fig. 4). The increases in $\beta_{1}$ per unit $\mathrm{pH}$ ranged between 0.97 and $1.64 \mu \mathrm{eq}(\mathrm{mg}$ DOC $)^{-1}$. These values are in the lower range of those calculated from the literature data for freshwater (1.16, 2.43, $3.44 \mu \mathrm{eq}(\mathrm{mg} \mathrm{DOC})^{-1}$ respectively Kortelainen 1992; Driscoll et al. 1994; Koehler et al. 1999). As in the case of freshwater, the increase in the formal charge with $\mathrm{pH}$ for atmospheric deposition is undoubtedly due to greater dissociation of the weak acids which constitute part of DOC, creating sites which may be protonated.

\section{CONCLUSIONS}

Validating the results of individual analyses is strongly recommended in the ICP Forests manual as a part of the routine laboratory activities (Ulrich et al. 2006). Validation should be performed as soon as possible after the chemical analyses have been completed when part of the sample is still available, so that, if needed, some of the determinations can be repeated. Validation is important for detecting both analytical random errors and transcription errors, the latter not being uncommon in the laboratory. If unexpected (abnormal) results are confirmed on the basis of the second set of analyses, these must be accepted and stored in the database.

The analysis of about 6000 data set allows us to conclude that, in addition to the validation techniques already described (Mosello et al. 2005; Ulrich et al. 2006), the DOC concentration can be successfully used in the ion balance to check the analysis of THR and STF samples. The simplest linear model was chosen to describe the relationship between the DOC concentration and the difference between cations and anions owing to the strong influence of analytical errors, which do not allow more sophisticated approaches. This was clearly demonstrated in our study by the strong influence on the total variance of the variable "laboratory" (one central laboratory for each country was included), which contributed $30 \%$ to the total variance. However, the statistics did not allow estimation of the extent to which the differences between the regression coefficients of each laboratory reflect systematic errors or real differences due, for instance, to the type of tree cover or the amount of precipitation. The type of deposition (THR or STF) and the relative importance of the marine salt contribution were of less relevance in the total variance; the factor "type of vegetation" proved to be less important, although significant, in determining the total variance $(0.5 \%)$, although the distinction between "conifers" and "broadleaves" is of course only a very general approach. In addition, the failure to quantify the contribution of other factors, such as the geographic location and climatic conditions on the plots (mean annual temperature and amount of precipitation), may be related to the large variance attributable to analytical errors.

The regression coefficients, $\beta_{1}$, obtained from the pooled data of the different laboratories gave DOC corrections that were close to the specific country coefficients. This suggest that the pooled $\beta_{1}$ values can be successfully used in evaluating the contribution of DOC to the ion balance in laboratories that did not participate in this study. The DOC correction, which was tested on an independent set of analysis results, considerably improved the applicability of the ion balance test for THR and STF solutions. The ion balance procedure should, together with the conductivity test, remain the primary reference method for validating the analyses.

However, it is strongly recommended to carry out specific studies in each laboratory, i.e. to test the regression between $\Delta$ and DOC as a part of the validation of the analytical results. These regression coefficients, after a comparison with those obtained in this study, will strongly increase the possibility of validating THR and STF results by the ion balance test, combined with the conductivity test.

\section{ACKNOWLEDGEMENT}

The authors acknowledge the financial contributions of the European Commission (under EC Regulation no. 2152/2003 Forest Focus) and national agencies.

\section{REFERENCES}

A.P.H.A., A.W.W.A. \& W.E.F. 2005. Standard methods for the examination of water and wastewater. $21^{\text {st }}$ ed. American Public Health Association, Washington.

Driscoll, C.T., M.D. Lehtinen \& T.J. Sullivan. 1994. Modelling the acid-base chemistry of organic solutes in Adirondack, New York, lakes. Water Resour. Res., 30: 297-306.

Hruška, J., H. Laudon, C.E. Johnson, S. Köhler \& K. Bishop. 2001. Acid/base character of organic acids in a boreal stream during snowmelt. Water Resour. Res., 37: 1043-1056.

Keene, W.C., A.A.P. Pszenny, J.N. Galloway \& M.E. Hawley. 1986. Sea-salt correction and interpretation of constituent ratios in marine precipitation. J. Geophys. Res., 91: 66476658.

Köhler, S., J. Hruska \& K. Bishop. 1999. Influence of organic acid site density on $\mathrm{pH}$ modelling of Swedish lakes. Can. J. Fish. Aquat. Sci., 56: 1461-1470.

Köhler, S., H. Laudon, A. Wilander \& K. Bishop. 2000. Estimating organic acid dissociation in natural surface waters using total alkalinity and TOC. Water Resour. Res., 34: 1425-1434. 
Kopáček, J., J. Hejzlar \& R. Mosello. 2000. Estimation of organic acid anion concentrations and evaluation of charge balance in atmospherically acidified colored waters. Water Res., 34: 3598-3606.

Kortelainen, P. 1992. Charge density of total organic carbon in Finnish lakes. Environ. Pollut., 77: 2-3.

Marchetto, A., R. Mosello, G. Tartari, J. Derome, K. Derome, P. Sorsa, N. Koenig, N. Clarke, E. Ulrich \& A. Kowalska. 2006. Atmospheric deposition and soil solution Working Ring Test 2005. E.U. Technical Report, Fontainebleau, France: $84 \mathrm{pp}$.

Miles, L.J. \& K.J. Yost. 1982. Quality analysis of USGS precipitation chemistry data for New York. Atmosph. Env., 16: 2889-2898.

Mosello, R., J. Derome, K. Derome, E. Ulrich, T. Dahlin, A. Marchetto \& G. Tartari. 2002. Atmospheric deposition and soil solution Working Ring Test 2002. E.U. Technical Report, Fontainebleau, France: 69 pp.

Mosello, R., M. Amoriello, T. Amoriello, S. Arisci, A. Carcano, N. Clarke, J. Derome, N. Koenig, G. Tartari \& E. Ulrich. 2005. Validation of chemical analyses of atmospheric deposition in forested European sites. J. Limnol., 64(2): 93102.

Received: January 2008

Accepted March 2008
Munsen, R.K. \& S.A. Gherini. 1993. Influence of organic acids on the $\mathrm{pH}$ and acid-neutralising capacity of Adirondack lakes. Water Resour. Res., 29: 891-899.

Oliver, B.G., E.M. Thurman \& R.L. Malcolm. 1983. The contribution of humic substances to the acidity of colored natural waters. Geochim. Cosmochim. Acta, 47: 2031-2035.

Schecher, W.D. \& C.T. Driscoll. 1987. An evaluation of uncertainty associated with aluminium equilibrium calculation. Water Resour. Res., 23: 525-534.

Ulrich, E., R. Mosello, J. Derome, K. Derome, N. Clarke, N. König, G. Lövblad \& G.P.J. Draajers. 2006. Part VI. Sampling and analysis of deposition. In: UN ECE. 2004. Manual on methods and criteria for harmonised sampling, assessment, monitoring and analysis of the effects of air pollution on forests. Hamburg (http://www.icpforests.org/pdf/Chapt6_compl2006.pdf).

UN ECE. 2004. Manual on methods and criteria for harmonized sampling, assessment, monitoring and analysis of the effects of air pollution on forests. International Co-operative Programme on Assessment and Monitoring of Air Pollution Effects on Forests. Hamburg (http://www.icpforests.org/Manual.htm). 